\title{
ABOGADO Y NADA MÁS QUE ABOGADO: MELQUÍADES ÁLVAREZ, JURISCONSULTO
}

\section{LAWYER AND NOTHING BUT LAWYER: MELQUÍADES ÁLVAREZ, JURISCONSULT}

\author{
José Luis Agudín Menéndez \\ Universidad de Oviedo
}

Recensión de / Review of: Manuel Álvarez-Buylla Ballesteros, Entre la ciencia del Derecho y el arte de la politica. Melquíades Álvarez, jurisconsulto, Ediciones de la Universidad de Oviedo, Oviedo, 2019, 286 págs. [Con prólogos de Santiago García Granda, Victoria Ortega Benito, Luis-Carlos Albo Aguirre y prefacio de Justo García Sánchez].

SUMARIO: I. MELQUÍADES ÁLVAREZ Y EL MELQUIADISMO EN PERSPECTIVA. UNA INTRODUCCIÓN HISTORIOGRÁFICA NECESARIA. METODOLOGÍA Y FUENTES NOVEDOSAS DE LA TRILOGÍA MELQUIADISTA.- II. MELQUÍADES AL DESNUDO: A PRÓPOSITO DE LA OBRA DE ÁLVAREZ-BUYLLA: EL PERFIL HUMANO Y COMO JURISTA DE MELQUÍADES ÁLVAREZ.- III. A MODO DE CONCLUSIÓN. HACIA UNA BIOGRAFÍA TOTAL DEL FUNDADOR DEL PARTIDO REFORMISTA.

Palabras clave: Biografia, Melquíades Álvarez, Colegio de Abogados de Madrid, Partido Reformista, Derecho Penal.

Key Words: Biography, Melquíades Álvarez, Madrid Bar Association, Reformist Party, Criminal Law.

\footnotetext{
"Sólo en Melquíades Álvarez coincidian dos personalidades: la jurídica y la política, que se complementan y son indivisibles en las relaciones del hombre público-dirigente con el Estado".

Antonio L. Oliveros, Asturias en el resurgimiento español. Apuntes históricos y biográficos, Silverio Cañada, Gijón, 1982, p. 364.

"Aunque resulta incuestionable su prestigio como letrado, sin embargo, Melquiades Álvarez es reconocido como político".

Manuel Suárez Cortina, "Melquíades Álvarez. Fundador del reformismo", La Aventura de la Historia, $\mathrm{n}^{\circ}$ extraordinario (noviembre de 2014), p. 103.
} 


\section{MELQUíADES ÁLVAREZ Y EL MELQUIADISMO EN PERSPECTIVA. UNA INTRODUCCIÓN HISTORIOGRÁFICA NECESARIA. METODOLOGÍA Y FUENTES NOVEDOSAS DE LA TRILOGÍA MELQUIADISTA}

En más de una ocasión el historiador Manuel Suárez Cortina ha subrayado la condición de abogado de Melquíades Álvarez y González-Posada (1864-1936) por sus años de ejercicio en activo y por haber sido designado, al inicio y al final de su meteórico cursus honorum, decano del Colegio de Abogados de Oviedo y de Madrid. Suárez Cortina en absoluto omitía la formación académica de Álvarez en los mimbres de la ciencia del derecho ni tampoco su etapa como catedrático de Derecho Romano en la Universidad de Oviedo. En uno de los discursos que el autor de la obra objeto de esta recensión transcribe, en concreto el de su investidura como Decano del Colegio de Abogados de Madrid, Melquíades admitía que prefirió considerarse antes abogado que politico y profesor universitario. La trayectoria politica del tribuno gijonés Melquíades Álvarez ha sido merecedora a lo largo de estas últimas décadas de más de una veintena de libros, artículos académicos y capítulos de obras colectivas. Mientras que algunas de las contribuciones de historiadores como el mencionado Manuel Suárez Cortina trazaron los senderos de la deriva del unionismo republicano y del Partido Reformista y su no menos conocida teoría de la accidentalidad de las formas de gobierno en la antesala del inicio de la dictadura de Primo de Rivera ${ }^{1}$, otras como las de Luis Iñigo Fernández exploraban el crepúsculo del proyecto político reformista durante la II República. Ya para entonces el Partido Reformista se había transformado en el Partido Republicano Liberal Demócrata, un grupo político reducido a varias personalidades nostálgicas del pasado reformista y limitado geográficamente por sus adhesiones a Asturias y Salamanca ${ }^{2}$. E1 progresivo arrinconamiento al que le sometieron las fuerzas que encabezaron los designios del nuevo régimen, llevaría a Melquíades a alinearse durante el Bienio Radical-Cedista con los católicos accidentalistas, lerrouxistas, agrarios y monárquicos. A los trabajos de sendos autores les precedia una producción no muy extensa de panfletos y testimonios que hicieron su aparición coetáneamente al final de la carrera politica del tribuno gijonés, como la del literato pro-

1 Manuel Suárez Cortina, El reformismo en España. Republicanos y reformistas bajo la monarquía de Alfonso XIII, Siglo XXI editores, Madrid, 1986. También su tesis doctoral: Manuel Suárez Cortina, El Partido Reformista, 1912-1931, Tesis Doctoral, Universidad de Cantabria, 1985. Del mismo modo cfr. Algunos de sus artículos y capitulos de libro: "Melquíades Álvarez, liberal $y$ demócrata”, Bulletin d'Histoire Contemporaine de 1'Espagne, n 10, 1989, pp. 24-34, esp. p. 25; "Melquiades Álvarez y la democracia liberal en España", en Javier Moreno Luzón (edit.): Progresistas: biografias de reformistas españoles (1808-1939), Taurus, Madrid, 2009, pp. 233-270; "Melquiades Álvarez, fundador del reformismo", La Aventura de la Historia, n extraordinario, 2014, pp. 102-107; y "Melquíades Álvarez, el reformismo y la cultura institucionista", en Sergio Sánchez Collantes (edit.): Estudios sobre el republicanismo histórico en España. Luchas politicas, constitucionalismo y alcance sociocultural, Real Instituto de Estudios Asturianos, Oviedo, 2017, pp. 147-178.

${ }^{2}$ Luis Iñigo Fernández, Melquíades Álvarez. Un liberal en la Segunda República, Real Instituto de Estudios Asturianos, Oviedo, 2000, pp. 185 y ss.; Íd., "El Partido Republicano Liberal Demócrata, 1931-1936. Aspectos ideológicos y programáticos”, Espacio, Tiempo y Forma. Serie V, Historia Contemporánea, $\mathrm{n}^{\circ} 8,1995$, pp. 141-177, esp. p. 158. Con todo, cabe recordar que su aportación se insertaba dentro de un proyecto de doctorado más amplio que, bajo la dirección del historiador Julio Gil Pecharromán, abarcaba el conjunto de fuerzas del republicanismo conservador y constitucionalista. 
melquiadista Mariano $\mathrm{Cuber}^{3}$ y la de su ex-correligionario Antonio López-Oliveros: la imprescindible Asturias en el resurgimiento español (1935) ${ }^{4}$. Precisamente fue este último quien doce años después se embarcaría en una semblanza que luego sería rescatada por Jesús Mella para la editorial Silverio Cañada y que vio la luz en 19995. Otro de los libros más destacados en esta línea fue el del biógrafo Maximiano García Venero, que contó con un proemio del escritor Azorín ${ }^{6}$. También con anterioridad a las investigaciones de Suárez Cortina, Edward G. Gingold presentó una tesis doctoral que pasó completamente desapercibida puesto que ni tan siquiera habia sido objeto de publicación ${ }^{7}$.

Por desgracia y como advierte uno de los prologuistas de excepción que disfruta esta excelente obra, varios errores en el viraje del proyecto melquiadista desde tiempo antes de la caída de Alfonso XIII mancharon la trayectoria de Melquíades que difícilmente iba a ser reivindicada en los días álgidos de la Dictadura ni tampoco por las fuerzas hegemónicas de la actual democracia cuya Constitución de 1978 bebe de los postulados reformistas ${ }^{8}$. De hecho uno de los considerados padres de la Constitución - Miquel Roca- había intentado continuar la tercería vía reformista mediante la fundación del Partido Reformista Democrático logrando un escaso respaldo popular en las elecciones de ${ }^{1986^{9}}$.

3 Mariano Cuber, Melquíades Álvarez: El orador. El hombre. El politico. Sus ideales. Su consecuencia. Su integridad, Editorial Reus, Madrid, 1935.

4 Antonio López-Oliveros Fernández, Asturias en el resurgimiento español (Apuntes históricos y biográficos), Silverio Cañada, Gijón, 1982 [con introducción de Manuel Tuñón de Lara] [Ed. original: Imprenta de Juan Bravo, Madrid, 1935]. Si bien constituye una autobiografia y un testimonio de relieve para comprender el alcance del proyecto reformista y conocer de primera mano la evolución del diario gijonés El Noroeste, no es menos cierto que de modo explícito LópezOliveros traza la semblanza de Álvarez. Esta monografía apareció originariamente un par de años después de la dimisión de Oliveros del diario El Noroeste; dimisión que estuvo condicionada por la alianza del Partido Republicano Liberal Demócrata con las derechas en Asturias en las elecciones de 1933 así como el veto de Melquíades a la candidatura electoral del director del diario gijonés.

5 Antonio López-Oliveros Fernández, Melquíades Álvarez. Un tribuno español, Silverio Cañada, Gijón, 1999 [con prólogo de Sarah Álvarez de Miranda y edición e introducción de Jesús Mella].

6 Maximiano García Venero, Melquiades Álvarez. Historia de un liberal, Editorial Tebas, Madrid, 1974 [ed. original 1954].

7 Edward Gerard Gingold, Melquiades Álvarez and the Reformist Party, 1901-1936, Tesis Doctoral, University of Wisconsin, 1973. Su tesis, que formó parte de la hornada de historiadores norteamericanos que en los últimos años del franquismo mostró especial inquietud por la historia contemporánea de España, bebía mucho de la monografia que había dedicado Maximiano García Venero en la década de 1950, tal y como sostiene Francisco Manuel Balado Insunza, Gumersindo de Azcárate y Melquíades Álvarez: Entre el liberalismo y la democracia. Una aproximación politica, Tesis Doctoral, UNED, 2019, p. 105.

8 Justo García Sánchez, "Prefacio", en Manuel Álvarez-Buylla Ballesteros, Entre la ciencia del Derecho y el arte de la politica. Melquiades Álvarez, jurisconsulto, Ediciones de la Universidad de Oviedo, Oviedo, 2019, pp. 26-27.

9 Sobre la tercera vía reformista ha ofrecido algunas lúcidas reflexiones Javier Redondo Rodelas, "Los orígenes del reformismo en España. Melquiades Álvarez y la tercera vía como fórmula de superación de conflictos (1912-1936)", ponencia presentada en el X Congreso de la Asociación Española de Ciencia Política y de la Administración (Universidad de Murcia, 7-9 de septiembre de 2011), p. 2. Igualmente los usos del accidentalismo en formas de gobierno puestos en práctica por el reformismo pueden percibirse en los debates que tuvieron lugar en torno a la tramitación del proyecto constitucional. Al respecto vid. Francisco Manuel Balado Insunza, "La accidentalidad de las formas de gobierno en perspectiva histórica: Recurso para el acuerdo politico (1868-1978)", en Mónica Moreno Seco (edit.): Del siglo XIX al XXI: Tendencias y debates. Actas del XIV Congreso de 
Lamentablemente la figura de Álvarez quedaba oscurecida ante la reivindicación constante de la que eran objeto alguno de sus antiguos correligionarios y rivales politicos que lloraron su trágico final. Nos referimos, como no podía ser de otro modo, a Manuel Azaña o Niceto Alcalá-Zamora; presidentes que fueron de una república que no favorecía en demasía las expectativas de Melquíades. También aludimos a rivales politicos del socialismo como Indalecio Prieto. Al proceso de recuperación de la memoria de Álvarez no sólo han contribuido historiadores de talla como Suárez Cortina, Iñigo Fernández o el profesor honorario de la Universidad de Oviedo, José Girón Garrote ${ }^{10}$, sino también juristas como el exministro Fernando Suárez ${ }^{11}$ y los descendientes de Melquíades (Sarah Álvarez de Miranda y el propio Manuel Álvarez-Buylla) que han caracterizado el perfil humano, académico e intelectual del tribuno, abogado y profesor asturiano. La aportación que se procede a reseñar aquí constituye el broche de oro a una singular y original trilogía melquiadista que puede ayudar a construir lo que el profesor Justo García Sánchez acertadamente consideró como la biografía definitiva de Álvarez. Algo parecido por lo que este catedrático clama es la tesis que ha defendido hace poco tiempo el historiador Francisco Manuel Balado Insunza ${ }^{12}$. Pero, volviendo a la trilogia de Manuel Álvarez-Buylla, cabe resaltar que primeramente ha rescatado la Tesis Doctoral de Álvarez y confeccionado una edición crítica de la misma ${ }^{13}$, y en segundo término ha publicado una nueva antología de discursos siguiendo la estela que habia inaugurado el profesor José Girón Garrote ${ }^{14}$. No obstante, la faceta de Álvarez como jurisconsulto pasó bastante desapercibida a pesar de los estudios que el catedrático de Derecho

la Asociación de Historia Contemporánea, Universidad de Alicante, Alicante, 2019, pp. 645-659, esp. pp. 656-658.

No fue en vano el único proyecto político que bebió del legado melquiadista, ya que hace una década en Asturias el profesor Girón Garrote pareció percibir en Foro Asturias Ciudadanos una continuación del legado reformista que en más de una ocasión el partido liderado por Francisco Álvarez-Cascos reivindicó. Para más detalles: Ángel Mato y José Girón Garrote, "La tradición reformista: de Melquíades a Cascos", El Comercio, 26 de marzo de 2011, "Foro Asturias: Centrismo y reformismo", El Comercio, 15 de abril de 2011 y "El reformismo del siglo XXI", El Comercio, 19 de mayo de 2011.

10 Dentro de la colección de discursos parlamentarios que editó la Junta General del Principado de Asturias desde finales de la década de 1990. José Girón Garrote, "Estudio Preliminar", en Melquiades Álvarez, Antología de discursos, Junta General del Principado de Asturias, Oviedo, 2001, pp. IX-CLXXIII

11 Fernando Suárez González, Melquíades Álvarez. El drama del reformismo español, Marcial Pons-Fundación Alfonso Martín Escudero, Madrid, 2014.

12 Francisco Manuel Balado Insunza, Gumersindo de Azcárate y Melquíades Álvarez: Entre el liberalismo y la democracia. Una aproximación politica, op. cit.

13 Manuel Álvarez-Buylla Ballesteros, "Estudio Introductorio", en Manuel Álvarez-Buylla Ballesteros (edit.), Tesis Doctoral Inédita de Melquíades Álvarez, Ediciones de la Universidad de Oviedo, Oviedo, 2008, pp. 11-22.

14 Manuel Álvarez-Buylla Ballesteros, José Antonio García Pérez y Miguel Ángel Villanueva (edits.), Melquíades Álvarez. Discursos Parlamentarios, Ediciones Nobel, Oviedo, 2008. No obstante, las primeras antologias de discursos de Melquíades Álvarez datan del decenio de 1910, como lo fue la recopilada por el hermano del tribuno, Román Álvarez. 
Romano, el ya mencionado Justo García Sánchez, dedicó a los años en que Melquiades fue profesor en la Universidad de Oviedo ${ }^{15}$.

Esta monografía es el botón de muestra de más de dos décadas de una cuidadosa y rigurosa investigación en profundidad. Es todo un acierto por parte del Servicio de Publicaciones de la Universidad de Oviedo la edición de este encomiable libro; editorial que ya en su momento publicó la tesis doctoral de Álvarez perdida entre los fondos de la Unidad Bibliográfica y Documental de Tesis de la Biblioteca de la Universidad Complutense de Madrid. Una de sus grandes virtudes es que este trabajo no constituye ni mucho menos un cierre al tratamiento que merece la figura de Melquiades sino que abre la puerta a que otros historiadores o estudiosos del derecho se interesen por las fuentes juridicas que Manuel Álvarez-Buylla recopila. Desde luego uno de los puntos fuertes de la obra reside en la oportunidad que ofrecen fuentes como la Colección de Jurisprudencia Civil del Tribunal Supremo (1898-1936) mediante la cual se podía seguir las sentencias de cada uno de los casos que había defendido Álvarez y sobre todo las detalladisimas Colecciones de Sentencias del Tribunal Supremo. El hándicap de partida al que se enfrentaron tanto el propio Álvarez-Buylla Ballesteros como otros investigadores arriba señalados es el déficit de fuentes archivísticas por la desaparición de toda la correspondencia y memorias del jurisconsulto gijonés; documentación que fue pasto de la Guerra Civil. Dicho déficit pudo ser atajado no sólo por un análisis crítico de los testimonios sino también de las publicaciones derivadas de las conferencias donde se homenajeó a Álvarez con motivo del centenario de su nacimiento sin olvidar las contribuciones científicas que han visto la luz a lo largo de estos últimos decenios. Por medio de la lectura de todos estos tratados, Álvarez-Buylla pretendía llegar a las fuentes documentales originales descubiertas por otros biógrafos, periodistas, juristas e historiadores, y que tuviesen relación con la labor jurídica de Álvarez. Entre el amplio abanico de fuentes archivísticas cabe destacar, asimismo, el hallazgo de correspondencia que el tribuno mantuvo con Antonio Maura conservada en la Fundación de Antonio Maura (Madrid), el expediente académico de Álvarez en el Archivo General de la Administración (Alcalá de Henares), documentación judicial sobre su asesinato en el Archivo Histórico Nacional (Madrid), o las actas de gobierno del Colegio de Abogados de Oviedo. De igual forma el autor ha realizado un vaciado de información procedente de las colecciones de prensa histórica de Asturias, Madrid y de Francia.

Igualmente se conserva parte de lo que el autor sostiene que fue una enorme biblioteca de Melquíades Álvarez que su familia consiguió recuperar mal que bien. Álvarez-Buylla Ballesteros promedia que el número de títulos debió sobrepasar originariamente más de dos mil títulos. Quizás fuesen todavía muchos más, habida cuenta del minucioso sistema de catalogación organizado por Melquiades Álvarez. Ha llegado a nosotros por lo menos un 35\% de lo que el autor denomina su "biblioteca vivida". Y es que en ella se puede seguir la carrera de Álvarez desde sus estudios de licenciatura a la preparación de sus disertaciones académicas y pleitos. También se puede conocer sus aficiones literarias y hasta su colección histórico-politica que constituyó una de las bases sobre las que el tribuno cimentó la construcción de sus discursos parlamentarios y electorales. De la

15 Justo García Sánchez, Melquiades Álvarez: Profesor universitario, Ediciones de la Universidad de Oviedo, Oviedo, 1988, ’pp. 9-58 [con prólogo de Santiago Melón Fernández]. 
biblioteca ofrece, al final de la monografia, una útil enumeración de los volúmenes conservados y cuidadosamente clasificados por materias (Derecho Romano, Civil, Hipotecario, Mercantil, Penal, Administrativo, Laboral, Constitucional, Canónico, Procesal, Historia del Derecho, Derecho General, Literatura, Historia, Politica, Economia, Filosofia, Ética y Moral, Sociología y Textos Legales). El autor brinda del mismo modo hipótesis sobre las procedencias de algunos de los libros que Melquíades adquirió o recibió como regalo.

\section{MELQUíades aL DESNUdO: A PRÓPOSITO DE LA OBRA DE ÁlVAREZ- BUYLLA: EL PERFIL HUMANO Y COMO JURISTA DE MELQUÍADES ÁLVAREZ}

La obra se estructura en seis capitulos en cierta medida desequilibrados por la preponderancia que el autor concede en dos de ellos a los trascendentales decenios de 1910 y 1930. En todo caso, el núcleo de interés de la obra radica en el estudio de los pleitos judiciales de los que Melquíades informó ante el Tribunal Supremo, así como el papel desempañado por el tribuno en la política llevada a cabo tanto desde el Colegio de Abogados de Oviedo como el de Madrid. En ocasiones, la faceta de letrado se superpone perfectamente a la de político. De otro modo no se entendería que su proverbial don de la palabra manaría, como acertadamente indicó Suárez Cortina, de su curtimiento en el terreno de la abogacía $^{16}$. Conviene advertir que Álvarez-Buylla no ofrece un estudio pormenorizado de todos los pleitos en los que se implicó Melquíades Álvarez, sino que recoge una muestra significativa en función de la extracción social de sus clientes y el renombre de las entidades industriales, bancarias y empresariales de Madrid, Asturias y de otras provincias para las que actuó como defensor, o que fueron causas célebres. También coadyuvaría como otro factor de elección la relevancia que todos estos contenciosos tuvieron en la prensa de la época.

El primero y segundo de los capítulos estudian la formación académica y sus comienzos en el ejercicio jurídico en Asturias. Melquíades nace en el seno de una familia de extracción social modestísima en las cercanías del inicio del Sexenio Democrático. En el testimonio que recoge Álvarez-Buylla, Álvarez recordaba con nostalgia como había presenciado con su abuelo la proclamación de la I República. El fallecimiento del padre de Melquíades le obligó a simultanear su instrucción educativa con la ayuda que brindó en todo momento a su madre y a sus hermanos para aliviar las penurias económicas; penurias que todavía subyugarian a su familia hasta que ultimase con éxito su licenciatura en Derecho Civil y Canónico por la Universidad de Oviedo. También obtuvo rédito de sus colaboraciones periodísticas e incluso llegó a fundar un rotativo. Durante la etapa universitaria fraguó su interés por la política, sobresaliendo su admiración por el dirigente del republicanismo posibilista Emilio Castelar, y desarrolló su militancia republicana en torno al combate del caciquismo de Alejandro Pidal y Mon. Sin embargo, aquel ímpetu contestatario le acarreó denuncias judiciales. Obtuvo el grado de doctor en Derecho Penal por la Universidad Central de Madrid merced a una tesis que el autor de esta obra no sólo se limita a analizar sino que la encuadra sobriamente en el contexto de evolución de las teorías del Derecho Penal. En la etapa universitaria, Melquíades conocería a los que serían luego amigos y compañeros de bancada parlamentaria y con los que lideraría el

16 Manuel Suárez Cortina, “Melquíades Álvarez y la democracia liberal”, op. cit., p. 240. 
proyecto reformista como Gumersindo de Azcárate (quien a la sazón fue su director de tesis) y Ramón Álvarez-Valdés. Algunos de los ideales del programa reformista se perciben, tal y como advierte Álvarez-Buylla, en los contenidos de la Tesis Doctoral de Álvarez. En concreto, se trata de las propuestas teóricas de la corrección sobre el Derecho Penal del filosofo Karl Christian Krause, pero también del papel orientador de la religión o la educación. Esta última se convertiría luego en una de las piedras angulares de su programa politico. Como es bien conocido, el krausismo impregnaría tanto a la receta aplicada en los tiempos en que Álvarez había formado parte del Grupo de Oviedo como al ideario del Partido Reformista.

Poco después de doctorarse, Melquíades compaginó su ejercicio docente en la Universidad de Oviedo con la abogacía. De estas y otras cuestiones se ocupa el segundo de los capítulos de esta monografia. En un primer momento Melquíades fue profesor auxiliar de la cátedra de Derecho Romano y tardó prácticamente una década en acceder por oposición a esta misma cátedra en aquella Atenas del Norte. Y todo ello tenía lugar tras haber intentado infructuosamente opositar a la Cátedra de Derecho Natural en la Universidad de Oviedo y a la de Derecho Romano en la Universidad Central. Eran los años del Grupo de Oviedo cuya proyección pública y compromiso cívico fueron determinantes en la extensión de la cultura como mecanismo de combate frente al caciquismo. Alli cultivaría su amistad con el literato espiritista Leopoldo Alas, Clarin. Fruto de su compromiso en la cruzada anticiquil, Álvarez-Buylla sostiene que en aquellos primeros años como letrado de Melquíades Álvarez, éste no consiguió atraer una clientela adinerada sino a comerciantes humildes y pequeños propietarios agrarios. De todos modos, a finales de siglo, presentó su primer recurso de casación en el Tribunal Supremo a favor de los albaceas del Marqués de Vista Alegre en contra de los colonos legatarios que trabajaban sus tierras. Su preferencia no fueron las causas criminales sino los asuntos mercantiles y civiles, que tanto le llegaron a apasionar. En aquel contexto finisecular Melquíades accedió además a la presidencia del Colegio de Abogados de Oviedo a consecuencia de la preocupación que evidenció en todo momento por la situación profesional de sus compañeros colegiados.

El capítulo tercero se centra en la instalación de su despacho de abogados en Madrid, al poco de lograr su acta de diputado por la circunscripción de Oviedo, lo que no significó que Melquíades perdiese contacto con su tierra natal. Su primera intervención parlamentaria versó sobre la Instrucción Pública y la denuncia de la mala remuneración de los profesores auxiliares de universidad. No hubo mejor reclamo publicitario para su bufete de abogados que sus discursos en el Parlamento, dada la repercusión que la prensa de Madrid y de provincias le concedió. Sin embargo, Melquíades Álvarez no lo tuvo fácil en la atracción de una nueva clientela ya que en la competencia figuraban letrados de portentoso prestigio: Antonio Maura, Francisco Bergamin, Juan de la Cierva, Niceto AlcaláZamora o Ángel Ossorio y Gallardo. Asimismo, Manuel Álvarez-Buylla sugiere, por medio de la consulta de la sección de Crónica de Tribunales de la Revista de los Tribunales $y$ de Legislación Universal, que las publicaciones jurídicas constituyesen otro buen escaparate y vía de promoción para su bufete de abogados. De este modo, el gijonés comenzó a ganar fama entre el foro de togados. El autor selecciona del período que comprende la primera década del siglo varios casos en función de la notoriedad que llegaron a adquirir en la 
opinión pública. Así ocurrió con el conocido como el Pleito de la Casa Real, en el que Melquiades intermedió entre los representantes legales del Rey y los de los hijos ilegitimos de Alfonso XII y la artista Elena Sanz; la presentación de un recurso de casación por el mediático crimen de Mazarete, que generó una nueva "revuelta de intelectuales" y provocó cambios en la legislación judicial; o la memorable defensa que hizo del exitoso ingeniero Eugenio Ribera tras su procesamiento por ser responsable del siniestro en la construcción del Depósito de Agua de Madrid. Álvarez-Buylla pone en antecedentes al lector de todos los entresijos que envuelven a cada uno de los litigios de los que Melquíades informó ante el Tribunal Supremo. Con sus antiguos compañeros del Claustro universitario -Rafael Altamira y Adolfo A. Buylla- y sus correligionarios políticos -Azcárate y Lucas Merediz- Melquíades Álvarez impulsó el hasta ahora desconocido Centro Jurídico Gijón con sede en Madrid y Asturias ${ }^{17}$. En pleno desenvolvimiento minero, industrial y bancario sin olvidar tampoco la repatriación de capitales desde las Antillas a Asturias, Melquíades fue habilidoso a la hora de poner en marcha un bufete interprovincial que ofrecia, entre otros servicios, consultas en materia de derecho privado internacional, redacción de estatutos y Bases para la construcción de sociedades de todo género o la elaboración de informes acerca de las concesiones de minas, ferrocarriles o de cesiones o permutas. A pesar de que se desconoce el alcance del Centro Jurídico Gijón, puesto que el autor supone que su existencia no debió ser extensa en el tiempo ni que las relaciones entre sus componentes fuesen armoniosas, cabe preguntarse si entre quienes contrataron aquellos asesoramientos estarian las futuras clientelas políticas que se adscribirian al Partido Reformista. Si bien no disfrutó de una cómoda y holgada base social, lo cierto es que el melquiadismo fue apoyado por los indianos que dejaron su impronta en Asturias ${ }^{18}$.

Cuando Melquíades fundó el Partido Republicano Reformista en 1912reconvertido en 1913 en Partido Reformista-, el asturiano ya había alcanzado la cénit en la carrera de la abogacía al ser reconocido como abogado de primera categoría. El capitulo cuarto, en este sentido, se adentra en la vertiginosa segunda década de siglo. Para entonces el bufete de Melquíades Álvarez informaba ante el Tribunal Supremo de pleitos que afectaban a los simpatizantes y militantes del Partido Reformista. De igual forma, el tribuno gijonés aceptó la defensa de casos de clientes adscritos a los distritos y circunscripciones electorales por los que Melquíades había resultado electo. Esta fue una constante durante la Restauración, como constata el autor. Como es obvio, fue diputado por su natal Asturias a largo de su carrera como parlamentario en la Restauración y la II República. Al calor de la fundación del Partido Reformista, también lo haria en Alcázar de San Juan. Cuando fue parlamentario por este distrito conquense, Álvarez asumió la defensa de un caso de testamentarias en el Tribunal Supremo; recurso de casación que perdería. Asimismo la notoriedad que había alcanzado Álvarez había sido aprovechada a nivel publicitario por parte de casas de muebles, fabricantes de aspiradoras y productores de cerveza en una clara

17 Del que también se hace eco Francisco Manuel Balado Insunza, Gumersindo de Azcárate y Melquiades Álvarez, op. cit., pp. 391 y ss.

18 Jose Girón Garrote, "Los indianos: cultura y politica”, en Antonio Morales Moya (Coord.), Las claves de la España del siglo XX: La modernización social, Sociedad Estatal Milenio Nuevo, Madrid, 2001, pp. 217-232; y del mismo autor, Los partidos politicos en Asturias (1875-1923). Los partidos republicanos, reformista, socialista y comunista, Nobel, Oviedo, 2014, pp. 370-373. 
operación de lo que a dia de hoy como merchandising ${ }^{19}$. El hecho de que trabajase como representante del Banco Hispano-Americano o de la Sociedad Editorial de España seguramente tenía que ver con sus inclinaciones de ambas entidades hacia el reformismo. De esta manera no cabe olvidar que el subtitulado "diario democrático independiente" de Gijón, El Noroeste (1897-1936), a la sazón órgano oficioso del melquiadismo y dirigido a partir de 1917 por Antonio López-Oliveros, se había incorporado a aquella fórmula empresarial que congregaba a $\mathrm{El}$ Imparcial, El Liberal, El Heraldo de Madrid y El Defensor (Granada) ${ }^{20}$. Parece lógico pensar, en contra de lo que sugiere Manuel Álvarez-Buylla, que más que el apego que el diario El Liberal llegase a profesar por el reformismo, pesase más la adscripción de El Noroeste a la Sociedad Editorial de España -el celebérrimo Trust-. En cualquier caso, resultó infructuosa la defensa que Melquíades realizó del diario El Liberal, que había mancillado el honor de la joven María Josefa Mussó.

Melquiades también mantuvo la preocupación de antaño por la condición del abogado presentándose a las elecciones del Colegio de Abogados de Madrid. Álvarez-Buylla trae a colación de su labor como jurisconsulto el discurso parlamentario en el que puso al descubierto las irregularidades y arbitrariedades que habian envuelto al procesamiento de Francisco Ferrer i Guardia dos años después de la Semana Trágica, siendo consciente el tribuno de la inocencia del pedagogo ácrata. Afectadas por el complejo trasfondo político-social posterior a 1909 y 1919 estuvieron las defensas que el letrado realizó de los sindicalistas José Crespo y Manuel Villalonga. Otro de los aspectos más sugestivos que el autor analiza en esta obra es el de los dictámenes jurídicos escritos por Álvarez, que fueron publicados como modelo a seguir para otros especialistas de la ciencia del derecho. Desgraciadamente, la obra escrita de Álvarez no es prolija, adecuándose a la concepción del historiador del derecho Carlos Petit Calvo del "jurista perfecto de la España isabelina" que sólo disertaba y dejaba para un lugar subsidiario la producción escrita. Más allá de los prólogos de los que Melquíades fue autor y de su obra periodística de juventud, merecedora de un análisis en profundidad, no se pueden contar como escritos suyos sus discursos publicados a causa de que son meras transcripciones. La proliferación y difusión de estos discursos fue posible especialmente en el decenio de 1910 gracias a la labor que llevaron a cabo los círculos de sociabilidad melquiadistas.

En el siguiente capítulo que transcurre durante los directorios de Primo de Rivera el autor subraya el incremento de número de pleitos asumidos por su cada

19 En otras culturas politicas como las del carlismo y las del maurismo se cuentan con abundantes ejemplos. Cfr. Jordi Canal i Morell, Banderas blancas, boinas rojas. Una historia politica del carlismo, 1876-1939, Marcial Pons, Madrid, 2006, pp. 131-135 y María Jesús González Hernández, Ciudadanía y acción. El conservadurismo maurista, 1907-1923, Siglo XXI Editores, Madrid, 1990, pp. 149-150.

20 María Cruz Seoane y María Dolores Sáiz, Historia del periodismo en España. 3. El siglo XX: 1898-1936, Alianza, Madrid, 1996, pp. 76-77. Sobre El Noroeste y su vinculación con el Trust cfr. Jorge Uria, "El radicalismo democrático de El Noroeste", en Jorge Uría (coord.), Historia de la prensa en Asturias. I. Nace el cuarto poder. La prensa en Asturias hasta la Primera Guerra Mundial, Asociación de la Prensa de Oviedo, Oviedo, 2004, p. 202; Víctor Rodríguez Infiesta, Gijón y El Noroeste, 1897-1910: periodismo de empresa y publicidad periodistica en los inicios del siglo XX, Ateneo Obrero de Gijón, Gijón, 2005; del mismo autor: Socialización politica y prensa de masas: el proceso de opinión pública en Asturias, 1898-1923, Real Instituto de Estudios Asturianos, Oviedo, 2007, pp. 405-457, esp. p. 443. 
vez más prestigioso bufete. Dicho incremento se debía a que el golpe de estado del 13 de septiembre de 1923 significó un punto y aparte en la carrera política del dirigente. Lejos de mostrarse indiferente con la Dictadura, Melquíades se implicó en insurrecciones como la fallida Sanjuanada y se encargó de la defensa en los Tribunales de intelectuales (Fernando de los Ríos) o politicos (el exsenador liberal José García-Berlanga) perseguidos sañudamente por Primo de Rivera. Si bien en un principio el letrado gijonés habia rechazado hacerse cargo de la defensa de sociedades mercantiles por la crítica política que podria generar, en aquel decenio asesoró el contrato-concesión establecido entre la Compañía Telefónica Nacional y el Estado español. No habiendo percibido dádiva alguna de este asesoramiento, lo único que ha constatado Álvarez-Buylla es que seguramente algunos de sus pasantes y correligionarios reformistas obtuviesen influencia por medio de su nombramiento como abogados, asesores jurídicos o con puestos directivos de la Compañia Telefónica. También durante aquella década representó los intereses de la sociedad mercantil metalúrgica Orconera Iron Ore contra la Compañia Alemana Fried Krupp. Los intereses de dicha compañia de origen británico se hallaban en litigio desde el final de la Gran Guerra puesto que para los alemanes se había incumplido el contrato y la entrega del mineral de hierro. No era tampoco la primera ocasión que prestaba servicios para las grandes empresas puesto que se había convertido en el abogado predilecto de entidades crediticias como el Banco Hispano-Americano. De otro modo no se podría explicar que uno de los motivos del viaje que el leader reformista efectuó a tierras francesas durante la Gran Guerra fue el de convencer a los dirigentes galos de retirar de sus listas negras al Banco Hispano-Americano. Estos desempeños jurídicos para la banca y la industria-en especial el de la Compañia Telefónica-, que le valdrian duros - hasta injustos - vilipendios politicos por parte de sus rivales y antiguos seguidores durante la II República, contribuyeron enormemente a erosionar sus puntos de vista cuando funda el Partido Republicano Liberal Demócrata. Así lo advierte el autor a partir del testimonio de López-Oliveros.

Por último, Manuel Álvarez-Buylla se detiene de modo pormenorizado a estudiar el papel que el dirigente jugó durante la II República desentrañando hechos no bastante conocidos hasta el momento. Sin gozar de la relevancia política que mereció en su momento, Melquíades resultó elegido como Decano del Colegio de Abogados de Madrid en marzo de 1932, tras dos fructuosos intentos de elección (en 1923 y 1930). Su principal cometido al frente del Colegio fue la defensa de la independencia del poder judicial, uno de los caballos de batalla del programa del Partido Reformista. Se enfrentó al poder ejecutivo por legislaciones tan lesivas que minaron el prestigio de la joven República como la polémica Ley de Defensa de la República; ley a la que nunca se pretendieron doblegar algunos jueces a los que el Colegio de Abogados madrileño brindó su apoyo al ser sancionados por el Ministerio de Gobernación. Durante su decanato también se celebró el primer Congreso de la Unión Nacional de Abogados, organización que Álvarez había impulsado como derivada de la Unión Internacional de Abogados. Desde el Parlamento y el propio decanato se trató de impulsar el Estatuto General de la Abogacía que quedó en agua de borrajas, entre otras cosas, por la inestabilidad gubernativa y por el temor del Estado republicano a que los abogados compusieran, por medio de una federación de cada uno de los colegios de abogados provinciales, un formidable grupo de presión. El autor arroja nuevas luces, a partir de fuentes inéditas como las cartas del pasante de Melquíades, Hipólito Jiménez, sobre la implicación de Melquíades en la Sanjurjada. Hasta 
entonces, historiadores como Manuel Suárez Cortina apuntaban que "no hay pruebas de la participación de Melquíades Álvarez en el golpe de Sanjurjo [...], pero todo parece indicar que estaba al corriente del mismo" 21 . Las arbitrariedades desde el punto de vista jurídico del Gobierno de la República generaron problemas sociales y el incremento de la criminalidad, azuzados además por la crisis económica. Estos factores habrian coadyuvado al respaldo del golpe de estado del militar pamplonés por parte de hombres civiles adscritos al sector del constitucionalismo como el propio Melquíades Álvarez o Manuel Burgos y Mazo, antaño partidario de Ramón Nocedal. En cuanto a las defensas judiciales de las que se Álvarez encargó cabe destacar que, fruto de la aprobación de la Ley del Divorcio, su bufete de abogados se especializó en el derecho de familia. Sin importar el pelaje ideológico y social de sus defendidos y siempre y cuando les asistiese la razón, Álvarez no tuvo inconveniente en defender a personalidades vinculadas con el régimen caído como Dámaso Berenguer o a los funcionarios despedidos por la CAMPSA. Esta Compañia había sido creada precisamente en los años en que Melquíades asesoró a la Compañía Telefónica.

Asimismo, el trágico asesinato del jurisconsulto y político en la Cárcel Modelo de Madrid a mediados de agosto de 1936, fruto de lo que Álvarez-Buylla conceptualizó como las "tres tiranías", es otro de los asuntos estudiados en profundidad en la monografia. El autor da una vuelta de tuerca a este acontecimiento ya que había sido objeto anteriormente de una conferencia que impartió en la Real Academia de Jurisprudencia y Legislación ${ }^{22}$. La asunción de la defensa de su compañero colegiado José Antonio Primo de Rivera fue una temeridad, sumándose así otro de los factores que convertirian a Álvarez en el blanco predilecto de los ataques de sus antiguos seguidores y aliados del socialismo. Estos nunca le perdonarian la actitud crítica y serena que sostuvo contra la deriva del régimen republicano ni menos aún su firmeza contra los politicos y dirigentes sindicales implicados en la insurrección defensiva de octubre de 1934. Álvarez-Buylla, en fin, argumenta que Melquíades Álvarez no fue víctima de las turbas violentas sino de un complot político que contó con la aquiescencia de un gobierno que en modo alguno podría ser considerado su autor directo. La vibrante reconstrucción del magnicidio se apoya en testimonios periodísticos y memorísticos como los de Ramón Serrano Suñer y Arsenio de Izaga y archivísticos. Las conjeturas acerca de las responsabilidades parten de los documentos del secretario particular de Álvarez, Francisco Martínez Ramírez. Estas fuentes han ayudado del mismo modo a construir el relato que ofrece como colofón al diptico dedicado por el historiador Balado Insunza a las vidas cruzadas de Gumersindo de Azcárate y Melquíades Álvarez.

21 Manuel Suárez Cortina, "Melquiades Álvarez, el reformismo", op. cit., p. 175; Antonio LópezOliveros, Asturias en el resurgimiento, op. cit., pp. 323 y 326-327; Luis Iñigo Fernández, Melquiades Álvarez: Un liberal, op. cit., pp. 116-120.

22 Manuel Álvarez-Buylla Ballesteros, "El asesinato de Melquiades Álvarez: víctima de tres tiranias”, Torre de los Lujanes, 68 (2011), pp. 173-188. 


\section{A MODO DE CONCLUSIÓN. HACIA UNA BIOGRAFÍA TOTAL DEL FUNDADOR DEL PARTIDO REFORMISTA}

Manuel Álvarez-Buylla nos dispensa una monografia dirigida tanto al público especializado como al interesado en general por el género biográfico. Lejos de elaborar una semblanza almibarada, se trata de una construcción ecuánime donde el autor muestra a Melquiades con sus luces y sus sombras, sus virtudes y sus manías o sus triunfos y sus derrotas en los estrados judiciales. En cualquier caso, a la hora de afrontar estudios como el de la biografia, resulta inevitable que el investigador acabé concordando con los ideales de justicia y de democracia pregonados por Álvarez. Cabe recordar una entrevista que ofreció el historiador francés Maurice Agulhon en la revista L'Histoire a finales de la década de 1980, en la que éste reconocía que no era posible hacer historia sin simpatizar con el objeto de estudio ${ }^{23}$. Ahora bien, en el gran historiador de las sociabilidades convivian armónicamente el rigor histórico y el compromiso político republicano si bien renegaba de la etiqueta de historiador de izquierdas puesto que aborrecía la concepción de historia militante ${ }^{24}$.

Si hubiera que realizar algún reproche a esta magnifica obra, éste tendría que ver con que se constatan alguna que otra errata y errores históricos Alfonso XII no recibía por segundo apellido Habsburgo-Lorena sino Borbón-. Del mismo modo hubiera sido de desear una separación más estricta entre cada uno de los seis capitulos que configuran la monografia. En el terreno puramente interpretativo se echa en falta que el autor ahondase en el fecundo debate historiográfico que ha generado el estudio del Grupo de Oviedo al que Melquíades Álvarez estuvo vinculado en el período finisecular. De aquella época cumbre de la institución se cuentan con trabajos de relieve desde el firmado por Santiago Melón hasta los más recientes de Santos M. Coronas y Gustavo H. Prado, pasando por los dirigidos por Jorge Uría a finales de la pasada centuria ${ }^{25}$. Si bien Álvarez-Buylla Ballesteros constata una preponderancia de los valores republicanos y liberales, no es menos cierto que, de acuerdo con el propio Jorge Uría, en aquel claustro convivieron desde conservadores y tradicionalistas hasta institucionistas de amplio espectro liberal. A su modo de ver, "la composición del Claustro [...] tenía una estructura complicada, y el juego de coaliciones podía ser tan amplio como conflictivo"26. Al final de sus dias, Melquíades Álvarez se habia

23 Jordi Canal i Morell, "Maurice Agulhon y la historia", en Maurice Agulhon, Politica, imágenes y sociabilidades. De 1789 a 1889, Prensas Universitarias de Zaragoza, Zaragoza, 2016, p. 21.

24 Ibid., p. 21; Jordi Canal i Morell, La historia es un árbol de historias. Historiografía, politica, literatura, Prensas Universitarias de Zaragoza, Zaragoza, 2014, pp. 83-84.

25 Un estado de la cuestión asequible en Jorge Uría, "El Grupo de Oviedo: reforma social y proyección pública”, en Sergio Sánchez Collantes (edit.), Estudios sobre el republicanismo histórico, op. cit., pp. 182-201 Vid. Igualmente Santiago Melón, Un capitulo en la historia de la Universidad de Oviedo, 1883-1910, Instituto de Estudios Asturianos, Oviedo, 1963; Miguel Ángel Muñiz Fernández, "Extensión universitaria y cultura", en Historia General de Asturias, tomo 5, Silverio Cañada, Gijón, 1978, pp. 49-64; Jorge Uría, "La Universidad de Oviedo en el 98: Nacionalismo y regeneracionismo en la crisis finisecular española”, en Jorge Uría (Edit.), Asturias y Cuba en torno al 98, Labor, Barcelona, 1994, pp. 169-196; Jorge Uria (Edit.), Institucionismo y reforma social: El Grupo de Oviedo, Talasa, Barcelona, 2000; Santos M. Coronas, "El "Grupo de Oviedo" o la fuerza del ideal”, Boletín del Real Instituto de Estudios Asturianos, vol. 57, n ${ }^{\circ}$ 161, 2003, pp. 7-48; o Gustavo H. Prado, El Grupo de Oviedo en la historiografía y la controvertida memoria del krausoinstitucionismo asturiano, KRK, Oviedo, 2007.

${ }^{26}$ Jorge Uría, "El Grupo de Oviedo", op. cit., pp. 182 y 205. 
puesto en contacto con quien había sido otro miembro del Grupo de Oviedo como fue el carlista Jesús Arias de Velasco cuyo final no sería muy distinto al de Álvarez. En 1936, Arias de Velasco era presidente de la Sala Segunda del Tribunal Supremo. El anteriormente catedrático de Derecho Administrativo y rector de la Universidad de Oviedo habia sido premiado por el ministro de Justicia Fernando de los Ríos con una presidencia de la sala quinta de este mismo tribunal como premio a la oposición que mantuvo frente a la Dictadura de Primo de Rivera, en línea con la actitud del rey-pretendiente carlista Jaime de Borbón $^{27}$. No se comparten tampoco apreciaciones tajantes como la de que "las elecciones [de febrero de 1936] [...] fueran ganadas irregularmente por el Frente Popular"28. No cabe duda que en algunos distritos electorales irrelevantes así fuese. En cualquier caso estos hechos no resquebrajarian la ajustada, pero legítima, victoria de los partidos que integraron dicha coalición. Otra cuestión bien distinta serian las arbitrariedades que tuvieron lugar en las comisiones de actas con posterioridad a los comicios y que despojaron de sus actas a diputados como el propio Álvarez.

En todo caso, los aspectos arriba señalados no resquebrajan lo que representa un aliciente para la construcción de la biografia total de Melquiades Álvarez. Con impaciencia se espera, en este sentido, la aparición del trabajo de Balado Insunza que también aborda el papel desempeñado por Álvarez en los tribunales. No por casualidad, el trabajo de Álvarez-Buylla, como el de Fernando Suárez lo hizo en 2014, aparece como una reivindicación de su legado y su figura en un contexto como el actual caracterizado por la primacía de los maximalismos y personalismos políticos en detrimento de la búsqueda de consensos y concordias. La concordia había parecido brillar cuando la corporación municipal madrileña en su conjunto acordó honrar con una calle al tribuno gijonés ${ }^{29}$. Así

27 Para más detalles biográficos sobre Jesús Arias de Velasco vid. Constantino Suárez, Escritores y artistas asturianos. Índice bio-bibliográfico, Tomo 1, Gráficas Summa, Madrid, 1936, pp. 457-460; y “Arias de Velasco, Jesús", en Gran Enciclopedia Asturiana, Tomo 2, Silverio Cañada, Gijón, desde 1970, p. 5.

$28 \mathrm{Si}$ bien no es una cuestión que atañe a esta revisión bibliográfica baste con mencionar aquí la fecunda discusión que generó la aparición de la monografía del tándem Manuel Álvarez Tardío y Roberto Villa Garcia, 1936. Fraude y violencia en las elecciones del Frente Popular, Espasa, Madrid, 2017, ya que sobrepasó el terreno historiográfico y se convirtió en un arma arrojadiza instrumentalizada por medios de comunicación afines a la derecha en el debate público. Ahora bien, esta discusión comenzó inmediatamente después de la celebración de los comicios al ser azuzada la idea de fraude electoral por parte de diarios como el cedista El Debate o el alfonsino $A B C$. Para más detalles, las cuidadosas, aunque no coincidentes, revisiones de Enrique Moradiellos, "Las elecciones generales de febrero de 1936: una reconsideración historiográfica", Revista de libros, 13 de septiembre de 2017, accesible desde Internet: https://www.revistadelibros.com/discusion/las-elecciones-generales-de-febrero-de-1936unareconsideracion-historiografica [con acceso 26 de enero de 2021]; y de Eduardo González Calleja y Francisco Sánchez Pérez, "Revisando el revisionismo. A propósito del libro 1936. Fraude y violencia en las elecciones del Frente Popular”, Historia Contemporánea, n 58, 2018, pp. 851-881, esp. pp. 853 y 875 .

29 Pedro J. Ramírez, "Matanza en la Modelo: aquellos ojos de Melquíades”, El Español, 21 de agosto de 2016, accesible desde Internet: https://www.elespanol.com/opinion/carta-deldirector/20160820/149435057_20.html [con acceso 20 de enero de 2021]. En Oviedo y Gijón ya disfrutaba de un par de calles. En su natal Gijón fue posible gracias a la obra de Álvarez-Buylla que recogía los discursos parlamentarios del lider del reformismo. El director de esta publicación identificó paralelismos, en este y otros editoriales de esta misma publicación digital, entre el reformismo de Melquiades Álvarez y el partido Ciudadanos, comandado en 2016 por Albert 
pues, figuras como las de Melquíades Álvarez recobrarían de nuevo un indudable interés. Por el contrario, los desaciertos políticos de Álvarez han pesado como una losa, constituyendo una incomodidad su reivindicación para derechas e izquierdas. Igualmente, la aparición de esta obra se beneficia del contexto historiográfico sumamente benigno que disfruta a día de hoy el cultivo de la biografia histórica ${ }^{30}$. Y es precisamente en el campo de estudio de las culturas politicas republicanas, a las que se adscribiría en un inicio Melquíades Álvarez, donde más se ha prodigado este género ${ }^{31}$. Con este notorio cierre de la trilogía, Álvarez-Buylla nos regala no sólo una lectura indispensable más para los interesados en la trayectoria de Melquíades Álvarez sino también un punto de partida para futuras indagaciones que merezca la labor como jurista del político gijonés. A partir de su función como letrado no se puede entender el alcance de las decisiones políticas que Álvarez tomó. Dada su trascendencia, más allá de haber desempeñado la presidencia del parlamento poco antes del inicio de la Dictadura de Primo de Rivera, en ningún momento Melquíades aceptó ningún cargo ministerial por el alejamiento que supondría de los estrados judiciales. Su lugar fue ocupado, en cambio, por uno de los miembros más destacados de la guardia pretoriana del Partido Reformista, el también jurista José Manuel Pedregal Sánchez (1871-1948). El que fuera vástago del celebérrimo ministro de Hacienda durante la I República y posterior cabecilla del Partido Republicano Centrista, Manuel Pedregal y Cañedo (1831-1896), fue el primero de los ministros del reformismo que formó parte de un consejo de ministros. Álvarez-Buylla nos deja, además, algunas pistas para adentrarse en la carrera como jurista de Pedregal ya que se alude en el libro a un recurso de casación que presentaron ex aequo Álvarez y Pedregal poco después de arribar el tribuno gijonés a Madrid. Pedregal siguió los pasos de su padre, afamado letrado durante los años posteriores a la caída de la I República. Por ello, se recalca la necesidad de un estudio monográfico sobre la vida de José Manuel Pedregal que haga especial

Rivera. Cfr. Pedro J. Ramírez, "Los zorros y el armiño", El Español, 16 de mayo de 2015, accesible desde Internet: http://blog.elespanol.com/arponero/los-zorros-y-el-armino/ [con acceso 27 de enero de 2021] y "Pedro J.: "El papel que le corresponde a C's. es el de Partido Regulador"”, El Español, 18 de julio de 2016, accesible desde Internet: https://www.elespanol.com/espana/politica/20160718/140986295_0.html [con acceso 27 de enero de 2021]. También fue del mismo parecer el sentir de una de las descendientes del propio Melquiades Álvarez, Sarah Álvarez de Miranda: “Ochenta años del asesinato del político gijonés en la Guerra Civil/ Sarah Álvarez: "El único heredero politico de Melquíades Álvarez podría ser Albert Rivera"”, La Nueva España, 28 de agosto de 2016, accesible desde Internet: https://www.lne.es/asturias/2016/08/28/sarah-alvarez-unico-heredero-politico-19498437.html [con acceso 27 de enero de 2021].

30 Al respecto la reciente reflexión de Rafael Serrano García, "Biografías recientes para el siglo XIX español”, Ayer. Revista de Historia Contemporánea, no 119, 2020, pp. 319-332.

31 Como botón de muestra el trabajo modélico brindado por Eduardo Higueras Castañeda, Con los Borbones, jamás. Biografía de Manuel Ruiz Zorrilla (1813-1883), Marcial Pons, Madrid, 2015 o el trabajo coral coordinado por Eduardo Higueras Castañeda, Rubén Pérez Trujillano y Julián Vadillo Muñoz, Activistas, militantes y propagandistas. Biografías en los márgenes de la cultura republicana (1868-1978), Athenaica Ediciones Universitarias, Sevilla, 2018. Un ensayo ejemplar que combina distintos géneros historiográficos es el dedicado al líder del Partido Republicano Radical, Alejandro Lerroux: José Álvarez Junco, El emperador del Paralelo. Lerroux y la demagogia populista, Alianza, Madrid, 1990. Otra monografia desmitificadora y que se aprovecha de un conocimiento óptimo del utillaje de la historia cultural es el del hispanista Adrian Shubert, si bien no afecta al ámbito de estudio del republicanismo: Espartero, el Pacificador, Galaxia Gutenberg, Barcelona, 2018. 
hincapié en su doble faceta como jurista y político. Cabe felicitar, por último, tanto al autor como a la editorial por esta monografia que incluye además un selecto conjunto de fotografias e ilustraciones desconocidas del abogado provenientes de su archivo familiar.

Enviado el (Submission Date): 27/01/2021

Aceptado el (Acceptance Date): 15/03/2021 